\title{
A Typical Autism Associated with Elevated Gonadotrophin and Precious Puberty: A Very Rare Association or a New Clinical Syndrome?
}

\author{
Aamir Jalal Al Mosawi* \\ Advisor doctor, Baghdad Medical City and the Iraqi Ministry of Health, Iraq \\ *Corresponding author: Aamir Jalal Al Mosawi, Advisor doctor, Baghdad Medical City and the Iraqi Ministry of Health, \\ Baghdad, Iraq
}

\section{ARTICLE INFO}

Received: 崫 December 12, 2020

Published: 慧 January 20, 2021

Citation: Aamir Jalal Al Mosawi. A Typical Autism Associated with Elevated Gonadotrophin and Precious Puberty: A Very Rare Association or a New Clinical Syndrome?. Biomed J Sci \& Tech Res 33(2)2021. BJSTR. MS.ID.005377.

Keywords: Atypical Autism; Mental Retardation; Clinical Syndrome

\section{ABSTRACT}

Background: Autistic disorders have become increasingly called pervasive developmental disorders since the 1980s. They include five chronic disorders associated with significant early impairment in socialization, communication, and behavior. Autistic disorders have recently been called autism spectrum disorder mostly by the American psychiatric association, and the term pervasive developmental disorders has been used with the term autism spectrum disorder interchangeably. Atypical autism disorders (Pervasive developmental disorder not otherwise specified) include disorders with well defined clinical features such as significant mental retardation. The aim of this paper is to report the very rare association of atypical autism associated with mental retardation, elevated gonadotrophin and precious puberty in a girl from the province of Babel (Babylon) in Iraq.

Patients and Methods: The case of a 10-year old girl who had history of precocious puberty with breast development started before the age of four years, was referred from the province of Babel because of poor development of speech and communication skills that made her unable to join ordinary school was studied. Imaging studies of the brain and abdomen didn't show any abnormal findings, and the precious puberty was attributed to elevated gonadotrophin. The had other two health children and the family history for a similar condition was negative.

Results: The girl experienced significant delay of her developmental mile stones including motor, speech, and adaptive behaviors. At the clinic, she was poorly responding to her name and had minimal eye contact. She also had echolalia and showed a repetitive movement. The girl's mental age was estimated to be about four years.

Conclusion: The very rare clinical association of atypical autism associated with mental retardation, elevated gonadotrophin and precious puberty in an Iraqi girl is presented, and the possibility of a new clinical syndrome is suspected.

\section{Introduction}

Autistic disorders have become increasingly called pervasive developmental disorders since the 1980s. They include five chronic disorders associated with significant early impairment in socialization, communication, and behavior. Autistic disorders were first recognized by Grunya Efimovna Sukhareva in 1925, a Soviet pediatric psychiatrist who called these disorders autistic psychopathy. In general, most of manifestations of pervasive developmental disorders result from impairments in social interaction and communication and behavioral problems [1-9]. Autistic disorder which is also called classical autism was first described by Leo Kanner in 1943. Asperger syndrome was first described by Grunya Efimovna Sukhareva, and later by Hans Asperger in 1944. The autistic psychopathies described in 1925 by Grunya Efimovna Sukhareva and Hans Asperger were similar and characterized by the absence of significant impairment in language 
development and cognitive function. Lorna Wing was probably the first to use the term Asperger syndrome in the English-speaking medical community in her 1981 publication of a series of case studies of children showing similar symptoms. Uta Frith translated Asperger's paper to English in 1991 and published it as a book with Cambridge University Press [3,6].

Rett disorder was most probably first described in German language in 1966 by Andreas Rett, a pediatrician in Vienna. Bengt Hagberg, a Swedish pediatrician, published an English article in 1983 and named the condition after Rett [3,6,7]. Childhood disintegrative disorder (Heller syndrome) is a rare heterogeneous clinical syndrome that is distinctive from autism and Asperger syndrome. It is characterized by a significant developmental regression resulting in deterioration in behavioral and adaptive functioning including self-help skills with loss of language and social skills after a period of normal development for at least two years $[3,6,8,9]$. The condition was first reported in 1908 by Theodor Heller in his paper "Über Dementia Infantilis". He called the condition "Dementia infantilis" $[3,6,8,9]$. Atypical autism disorders (Pervasive developmental disorder not otherwise specified) may include disorders with well defined clinical features such as regressive autism and autism with significant mental retardation which seems to be also classifiable under idiopathic mental retardation with significant autistic features $[1-3,10,11]$. The aim of this paper is to report the very rare association of atypical autism associated with mental retardation, elevated gonadotrophin and precious puberty in a girl from the province of Babel (Babylon) in Iraq.

\section{Patients and Methods}

The case of a 10-year old girl who had history of precocious puberty with breast development started before the age of four years, was referred from the province of Babel because of poor development of speech and communication skills that made her unable to join ordinary school was studied. Imaging studies of the brain and abdomen didn't show any abnormal findings, and the precious puberty was attributed to elevated gonadotrophin. During the previous two years, the girl was treated with monthly depot GnRH analogue (Zoladex) suppression precocious puberty. The had other two health children and the family history for a similar condition was negative.

\section{Results}
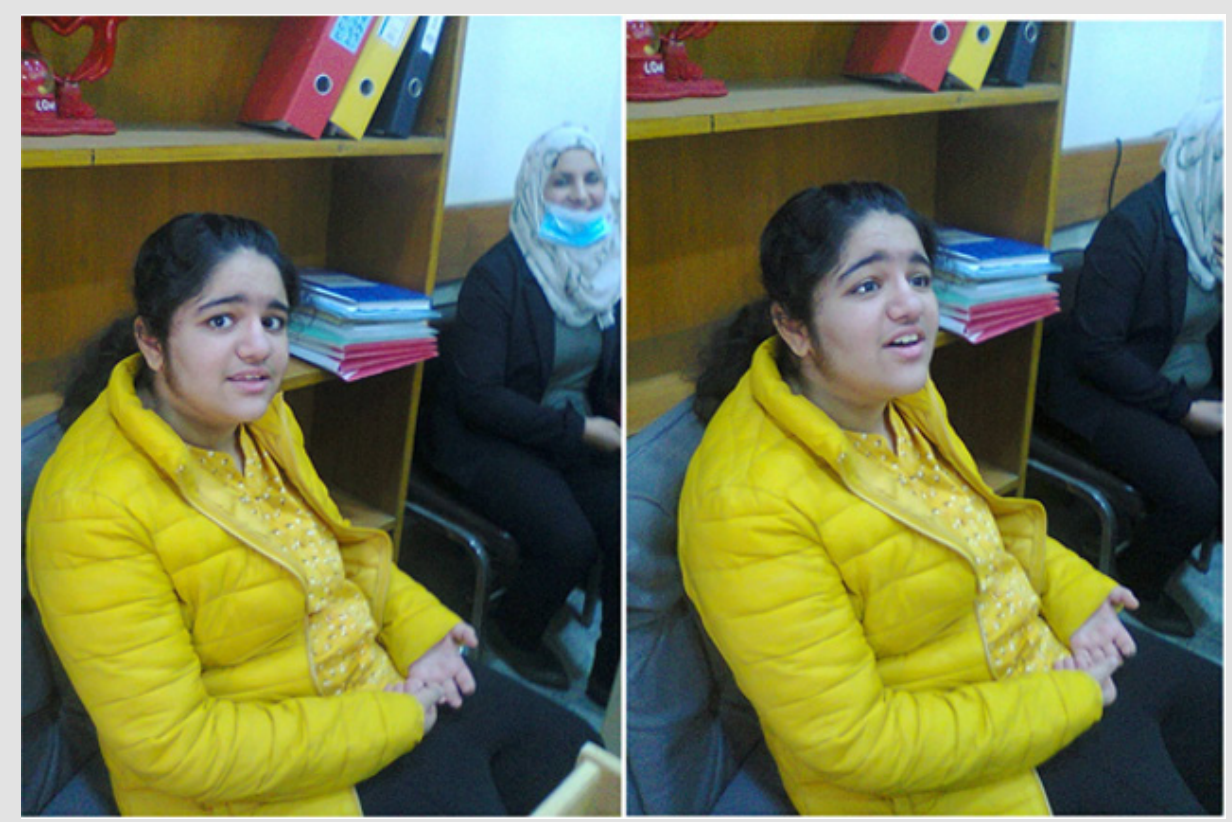

Figure 1: At the clinic, the girl was poorly responding to her name and had minimal eye contact.

The girl experienced significant delay of her developmental mile stones including motor, speech, and adaptive behaviors. She started walking after the age of four years. She started feeding self and controlling bowels after the age of six. She started saying few words after the age of eight after joining a special institute for handicapped children. At the clinic, she was poorly responding to her name and had minimal eye contact (Figure 1), and she was mostly replying but repeating the words. When she was asked
"How are you", she repeated "How are you", but the mother asked her to say, "I am fine", and she repeated" Fine, fine". However, it was possible to convince her to take a pen and draw and write what she likes. The mother said that she learned at the institute to write numbers, and she asked her to write numbers, the girl obeyed the mother and wrote numbers that were not very good. The girl also obeyed the request to copy a circle, a square and a triangle, but the triangle was very poor (Figure 2). 

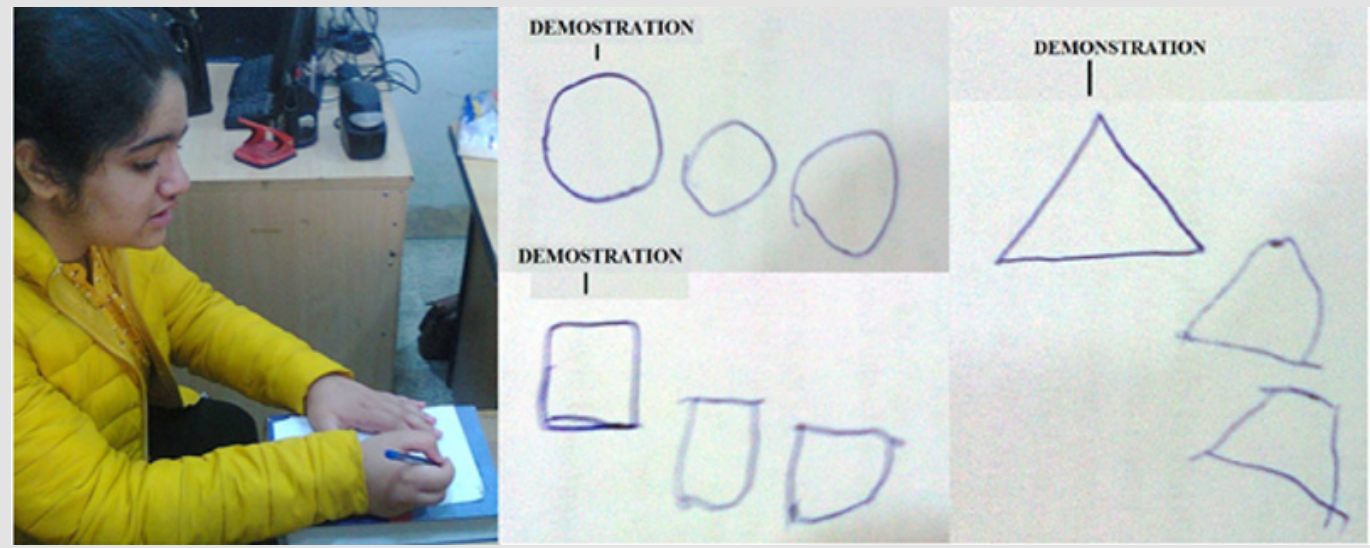

Figure 2: The girl obeyed the request to copy a circle, a square and a triangle, but the triangle was very poor.

The girl also displayed repetitive movement as when the pen fell from her hand to the ground she took it and threw it again and repeated that until the mother asked her to stop. Thereafter, the girl also obeyed the request to copy a diamond, and a man, but the diamond was very poor, while the man was acceptable (Figure 3). When the girl asked to imitate the doctor and stand on one foot, but she had difficulty in understanding. However, the mother helped in making her understand, and she was able to stand on one foot for few seconds. The girl's mental age was estimated to be about four years. When the girl asked to look at the camera to take a photo she avoided looking at the camera, and when they are leaving and the doctor said goodbye, and the parents asked her to wave and say goodbye she didn't obey them (Figure 4).
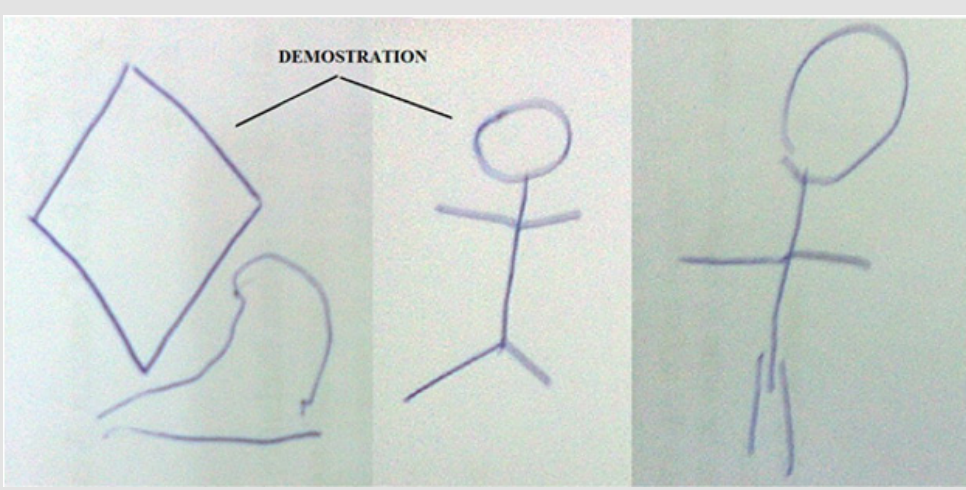

Figure 3: The girl also obeyed the request to copy a diamond, and a man, but the diamond was very poor, while the man was acceptable.

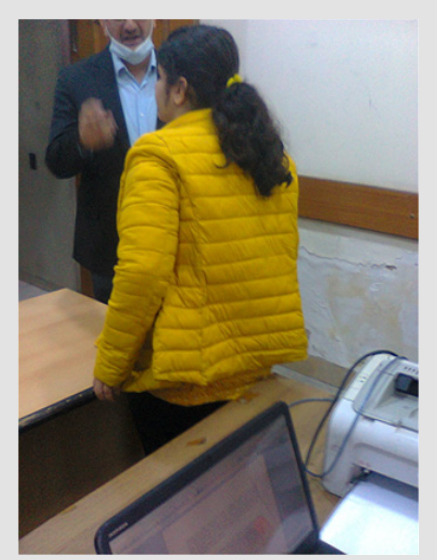

Figure 4: When they are leaving and the doctor said goodbye, and the parents asked her to wave and say goodbye she didn't obey them. 


\section{Discussion}

Curin, et al. [12] reported the association of autism disorders with elevated pituitary hormones including adrenocorticotropin (ACTH) [12]. Wannes, et al. [13] thought that non-idiopathic central precocious puberty can be caused by acquired or congenital hypothalamic lesions visible on MRI or results from a variety of genetic syndromic conditions. They reported 63 children (42 girls and 21 boys) with non-isolated central precocious puberty. 28 patients had hypothalamic lesions on MRI including 17 patients having hamartomas, and 8 patients having optic gliomas. Patients who didn't have brain MRI abnormalities included nine patients with narcolepsy, four patients with RASopathies, and seven patients with encephalopathy or autism disorders [13].

\section{Conclusion}

The very rare clinical association of atypical autism associated with mental retardation, elevated gonadotrophin and precious puberty in an Iraqi girl is presented, and the possibility of a new clinical syndrome is suspected.

\section{Acknowledgement}

The author would like to express his gratitude for the parents who willingly accepted publishing the girl's photos.

\section{Conflict of Interest}

None.

\section{References}

1. Al Mosawi AJ (2019) Pervasive developmental disorders in Iraqi Children. Journal of Psychiatry Research Reviews \& Reports 1(1): 1-8.
2. Al Mosawi AJ (2019) The pattern of pervasive developmental disorders in Iraqi children. ( $1^{\text {st }}$ Edn.). LAP Lambert Academic Publishing, Saarbrücken, Germany.

3. Al Mosawi AJ (2018) Pediatric psychiatry: An accredited training course. ( $1^{\text {st }}$ Edn.), LAP Lambert Academic Publishing, Saarbrücken, Germany.

4. Al Mosawi AJ (2020) Case studies in pediatric psychiatry: An approach to deep learning. ( $1^{\text {st }}$ Edn.), LAP Lambert Academic Publishing, Saarbrücken, Germany.

5. Al Mosawi AJ (2018) A new therapeutic approach for pervasive developmental disorders. ( $1^{\text {st }}$ Edn.). LAP Lambert Academic Publishing, Saarbrücken, Germany.

6. Al Mosawi AJ (2018) Asperger syndrome and regressive autism. (1 $1^{\text {st }}$ Edn.). LAP Lambert Academic Publishing, Saarbrücken, Germany.

7. Al Mosawi AJ (2019) New therapies for Rett syndrome. J Bio Innov 8(3): 301-307.

8. Al Mosawi AJ (2019) Childhood dementia: Heller syndrome. (1 ${ }^{\text {st }}$ Edn.). LAP Lambert Academic Publishing, Saarbrücken, Germany.

9. Al Mosawi AJ (2019) Heller syndrome in two Iraqi children. Clinical Research and Trials 5: 1-3.

10. Al Mosawi AJ (2020) Our experience with childhood pervasive developmental disorders (Autism and Asperger Syndrome): Cure is Possible. EC Clinical and Medical Case Reports 3(4): 1-8.

11. Al Mosawi AJ (2020) Cure of Autistic Disorders: Mission Impossible is Possible in an Illustrated Pioneering Experience. Archives of Health Science 4(1): 1-26.

12. Curin JM, Terzić J, Petković ZB, Zekan L, Terzić IM, et al. (2003) Lower cortisol and higher ACTH levels in individuals with autism. J Autism Dev Disord 33(4): 443-448.

13. Wannes S, Elmaleh Bergès M, Simon D, Zénaty D, Martinerie L, et al. (2018) High prevalence of syndromic disorders in patients with nonisolated central precocious puberty. Eur J Endocrinol 179(6): 373-380.

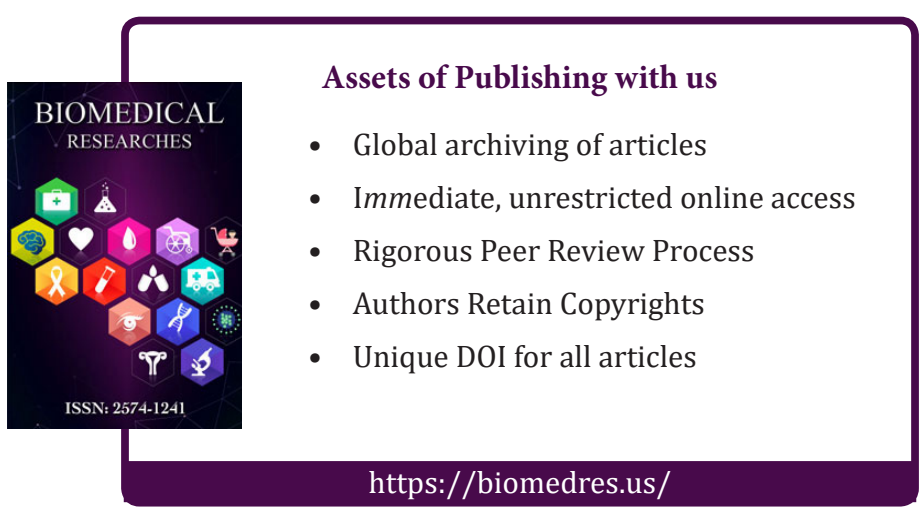

